\title{
Analysis of Herd Immunity on the Mathematical Model of Covid-19 Transmission
}

\author{
Mia Siti Khumaeroh ${ }^{1, *}$ Ahmad Firdaus ${ }^{2}$ \\ ${ }^{1}$ Department of Mathematics, UIN Sunan Gunung Djati Bandung, Indonesia \\ ${ }^{2}$ Faculty of Mathematics, Kyusu University, Japan \\ *Corresponding author.Email: miasitihumairoh@uinsgd.ac.id
}

\begin{abstract}
Many countries in the world, especially Indonesia, are still experiencing an increase number of Covid-19 cases despite the government has implemented many policies, such as an appeal for self-prevention, physical distancing, quarantine and large-scale social restrictions (LSSR) in several areas. Besides the health sector, this change in behavior or activity also has a major impact on other sectors such as education, tourism, economy etc. Herd Immunity, where a group in the population is given a treatment so that their body will be resistant to the virus, becomes another alternative to end this Covid-19 pandemic. In this study, we analyzed a mathematical model of corona virus transmission by involving the herd immunity factor. There are two schemes: (1) by using vaccines and (2) by allowing the virus to spread in the population and the result is the infected population have the immunity. The simulation results show that the use of vaccines can drastically reduce the number of infected individuals. On the other hand, the absence of virus transmission control can increase the number of exposed and infected individuals. However, in terms of time, this scheme will make Covid-19 cases decrease faster than other schemes.
\end{abstract}

Keywords: Herd Immunity, Covid-19, Mathematical Model, SEIR.

\section{INTRODUCTION}

The novel corona virus 2019 disesase (Covid-19), a disease that attacks the respiratory system, is spreading to almost all countries in the world. This disease has become a global health problem and has become the center of world attention [1]. On 17 November 2020, there were more than 54 million confirmed cases of coronavirus disease (Covid-19) with 1.3 million total deaths worldwide [2]. As in Indonesia, total cases have reached over 400 thousand cases with 15 thousand deaths make Indonesia as the country with the highest infected cases and mortality rates in Southeast Asia [2, 3].

In Indonesia, vaccine development is still in the clinical test [4]. A number of non-pharmaceutical interventions have also been applied to reduce the number of new cases, such as self-prevention, physical distancing, quarantine, and large-scale social restrictions (LSSR) in several areas. However, several countries are still experiencing an increase in the number of infected cases, including Indonesia. The total number of new infected cases in Indonesia fluctuates with an increasing trend [3]. This does not only impact on the health sector, other sectors such as the education, economy and tourism sectors are also affected.

After almost a year Covid-19 has become epidemic in the world with the increasing number of new cases in several countries, then the issue of implementing herd immunity has emerged. Herd Immunity occurs when a group of people in a population becomes immune to a disease thereby reducing the chance of spreading the virus through human interaction. As a result, the entire population can be protected from the virus, not only the immune groups [5]. Herd immunity is also defined as the level of population immunity at which the spread of disease will decrease and stop even after all preventive measures have been relaxed [6]. Herd immunity can be achieved either through the use of vaccines or by allowing the virus to live in the population, then the infected individual becomes immune to virus attack [7].

In this article, a mathematical model of Covid-19 transmission is analyze with the implementation of Herd Immunity. There are two schemes to be analyzed, (1) by 
involving the use of vaccines and (2) by allowing the virus to spreading in a population.

\section{MATHEMATICAL MODEL}

In this transmission model of Covid-19, the human population is divided into four compartments, namely susceptible (S), exposed (E), infectied (I), and recovered (R).

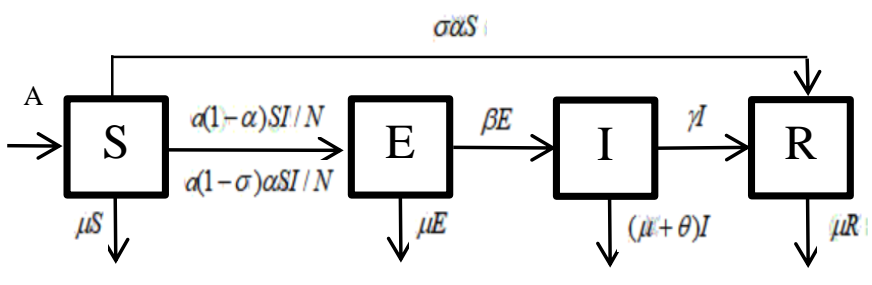

Figure 1 Compartment Diagram

The following assumptions are used in the first scheme by involving the use of vaccines. Some of the susceptible individuals who have been vaccinated turn into recovered individuals with a proportion of $\alpha(0 \leq \alpha$ $\leq 1)$, while the rest $(1-\alpha)$ have the opportunity to become exposed when there is interaction with infected individuals. Regarding the efficiency of the vaccine, susceptible individuals who have been vaccinated effectively block the transmission of the virus in a proportion $\sigma(0 \leq \sigma \leq 1)$, the rest $(1-\sigma)$ are likely to be infected. In this model it is assumed that only infected individuals can transmit the virus. In addition, there is a natural death in each compartment and death caused by viral infection of the infected compartment. A person who has recovered from an infection is assumed to be immune to the second infection. Description of each parameter on the compartment diagram can be seen in Table 1.

Table 1 Parameters Description

\begin{tabular}{cl}
\hline Parameter & \multicolumn{1}{c}{ Description } \\
\hline $\mathrm{A}$ & Recruitment rate \\
$\mathrm{a}$ & Effective contact rate of infected individual \\
$\alpha$ & Proportion of vaccine coverage \\
$\sigma$ & Proportion of vaccine efficiency \\
$\beta$ & Incubation rate \\
$\gamma$ & Recovery rate \\
$\Theta$ & Infection fatality rate \\
$\mu$ & Natural death rate \\
$\mathrm{N}$ & The total of population \\
\hline
\end{tabular}

The compartment diagram in Figure 1 can be represented by the following differential equations system.

$$
\begin{aligned}
& \frac{d S}{d t}=A-. a(1-\alpha) \frac{S I}{N}-a(1-\sigma) \alpha \frac{S I}{N}-(\sigma \alpha+\mu) S \\
& \frac{d E}{d t}=a(1-\alpha) \frac{S I}{N}+a(1-\sigma) \alpha \frac{S I}{N}-(\beta+\mu) E \\
& \frac{d I}{d t}=\beta E-(\gamma+\theta+\mu) I \\
& \frac{d R}{d t}=\sigma \alpha S+\gamma I-\mu R
\end{aligned}
$$

By assuming the birth rate equals to the mortality rate and total population is $\mathrm{N}=\mathrm{S}+\mathrm{E}+\mathrm{I}+\mathrm{R}$, then we obtain Basic Reproduction Number $\mathrm{R}_{0}$

$$
R_{0}=\sqrt{\frac{a \mu \beta(1-\sigma \alpha)}{(\beta+\mu)(\gamma+\theta+\mu)(\sigma \alpha+\mu)}}
$$

The basic reproduction number $\mathrm{R}_{0}$ is the number of secondary cases which one case would produce in a completely susceptible population [12].

The next scheme is a modified model which allow the virus to spread in a population, wherein the usage parameter vaccine is eliminated. This assumption is relevant considering we assume that immunity can be obtained when susceptible individual has experienced the infection process. Thus, the Basic Reproduction Number $\mathrm{R}_{0}$ for this scheme is

$$
R_{0}=\sqrt{\frac{a \beta}{(\beta+\mu)(\gamma+\theta+\mu)}}
$$

\section{PARAMETER ESTIMATION}

In this section, a dynamic simulation of virus transmission will be carried out involving two herd immunity schemes. Several parameters will be varied, such as the effective contact rate of infectious individuals (a), proportion of vaccine coverage $(\alpha)$, and proportion of vaccine efficiency $(\sigma)$. The value of a is proportional to the number of contacts between susceptible individual with infected individual and the success probability of that individual being infected. This parameter is also related to the prevention strategies of virus transmission such as selfprevention, physical distancing, quarantine, etc.

The average of incubation period for Covid-19, which is the first time an individual is exposed to the virus then show symptoms, is 5-6 days and the longest can be up to 14 days $[8,9]$. The recovery rate can be measured as a proportion of newly recovered individuals to the number of infected individual per day. 
Meanwhile, the death rate due to infection can be measured as a proportion of the number of new deaths to the number of infected cases per day. Both of recovery rate and death rate fluctuate every day, as seen in Figure 2. Recorded from August to October, the average of recovery rate is $4.96 \%$ and the average of death rate is $0.17 \%$.

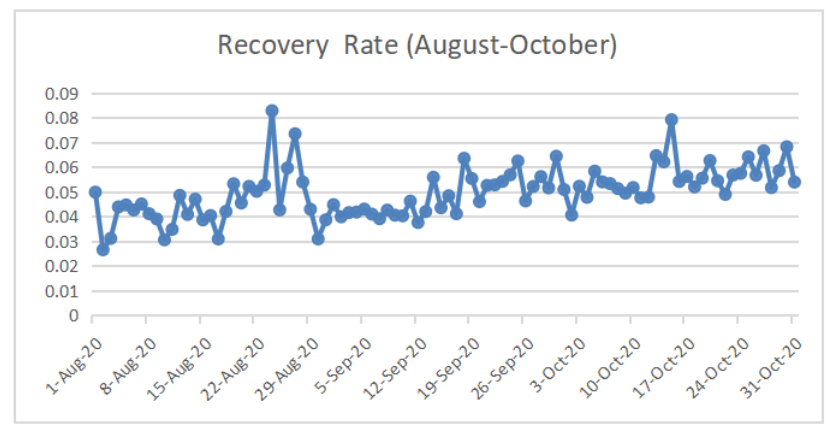

(a)

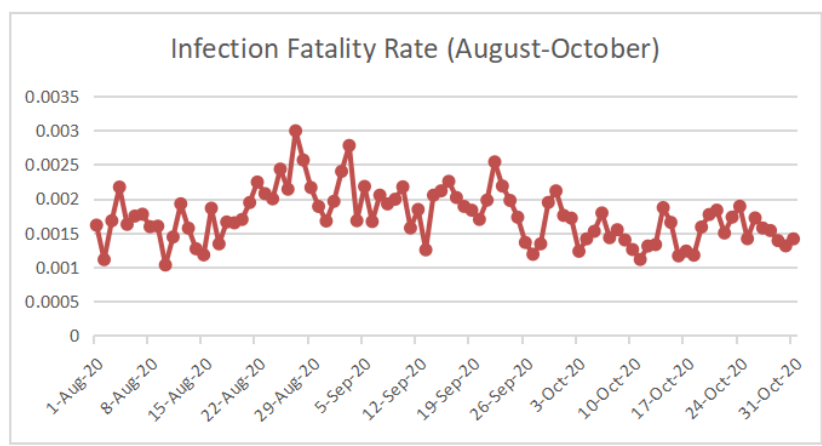

(b)

Figure 2. (a) Recovery Rate (b) Infection Fatality Rate [10]

Normalization is carried out in the simulation process, where the total population is $\mathrm{N}=1$. The birth rate is assumed to be equal to the death rate so that $\mathrm{A}=$ $\mu \mathrm{N}$. Estimation values of parameters used in the simulation process of cojvid-19 transmission model can be seen in Table 2.

Table 2. Parameters Estimation Value

\begin{tabular}{ccc}
\hline Parameter & Est. value & Ref. \\
\hline$\beta$ & $1 / 6$ & {$[8,9]$} \\
$\gamma$ & 0.0496 & {$[3]$} \\
$\Theta$ & 0.0017 & {$[3]$} \\
$\mu$ & $1 /(60 * 360)$ & {$[10]$} \\
$\sigma$ & 0.5 & {$[11]$} \\
\hline
\end{tabular}

\section{RESULT}

In the first scheme, dynamical simulation is presented with the vaccine coverage rate variation. As the meaning of herd immunity itself, the vaccines is given to a group of people so that individuals who do not vaccinate can be protected from virus transmission. The relatively expensive of vaccination, especially for new disease transmission, is also one of the reasons that not all individuals in the population must be vaccinated.

As a comparison, the simulation is carried out by giving the parameter value $\alpha=0$ which means that there is no vaccine, $\alpha=0.1$ or $10 \%$ of the population receive vaccine and $\alpha=0.2$ or $20 \%$ of the population receive vaccine. The results of the numerical simulation are shown in Figure 3.

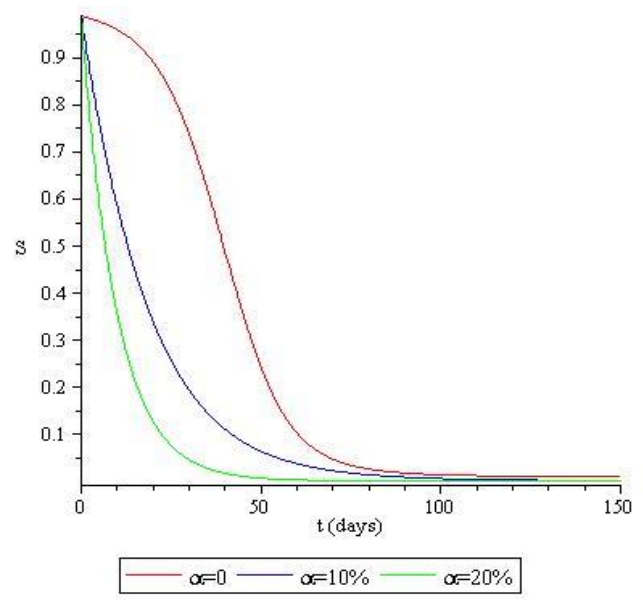

(a) Susceptible

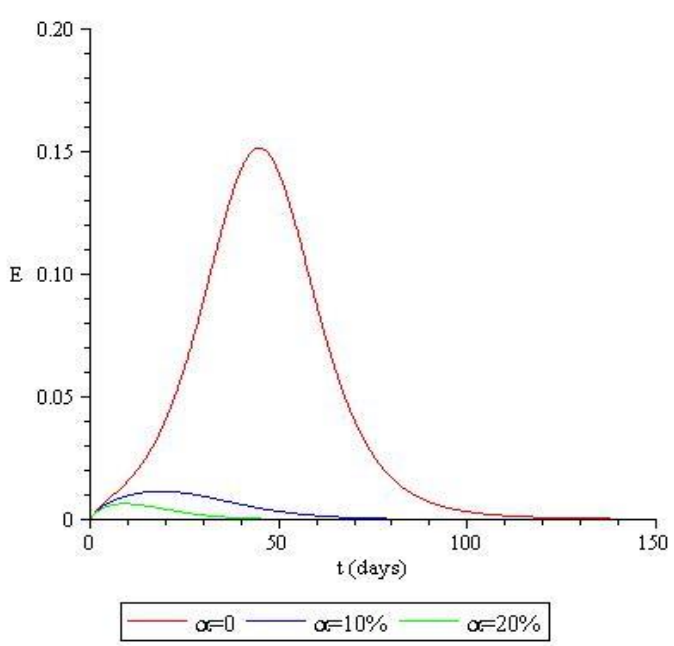

(b) Exposed 


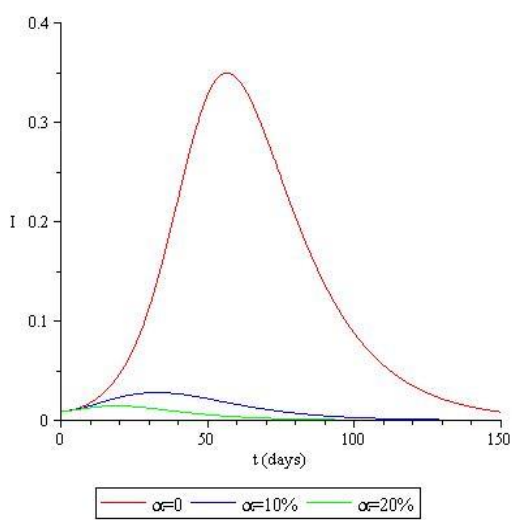

(c) Infectious

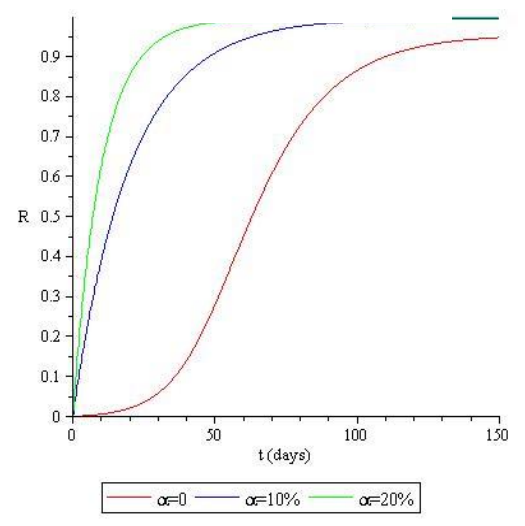

(d) Recovery

Figure 3. Dynamical simulation of SEIR with $a=0.25$ and infection coverage variation

With an effective contact rate $\mathrm{a}=0.25$, Figure 3 shows that in susceptible compartment, when many individuals are vaccinated then the number of susceptible individuals decreases faster than without vaccination. This is because many susceptible individuals become immune to the virus and switch to the recovered compartment. Whereas in the infectious compartment, the use of vaccines can drastically reduce the number of infected individuals.

Furthermore, for the second scheme, the simulation is carried out by taking the value $\alpha=0$, which is the assumption that there is no vaccination process and the virus is allowed to spread, so that immunity can be obtained from the infection process. The effective contact rate of infected individuals is also varied, because in this scheme we assume all activities enter the new normal.

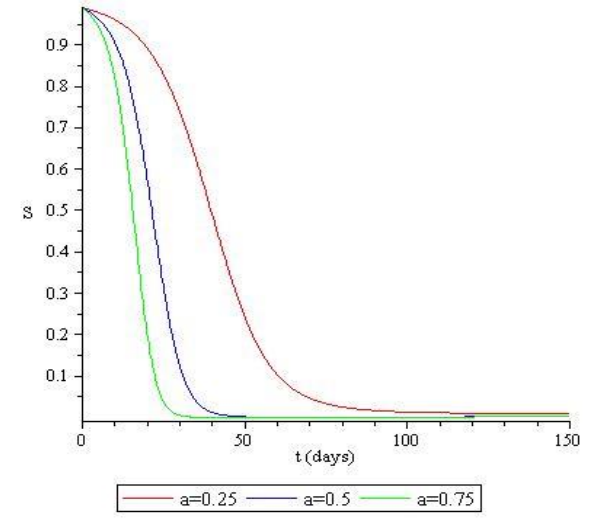

(a) Susceptible

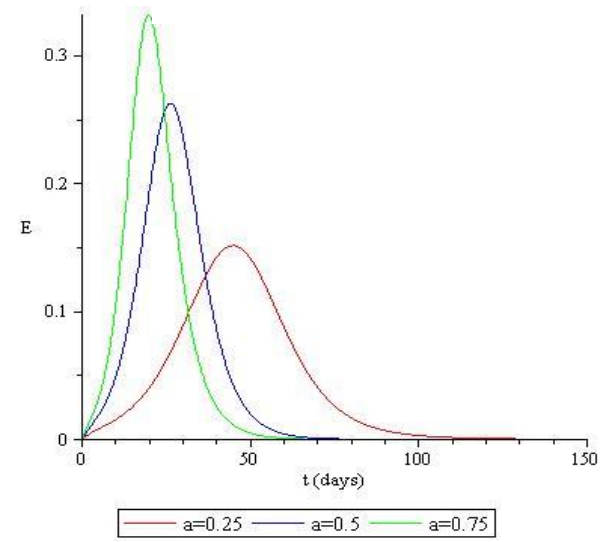

(b) Exposed

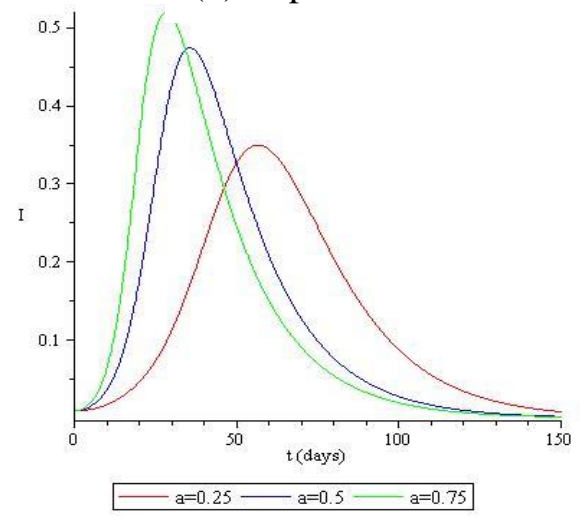

(c) Infectious

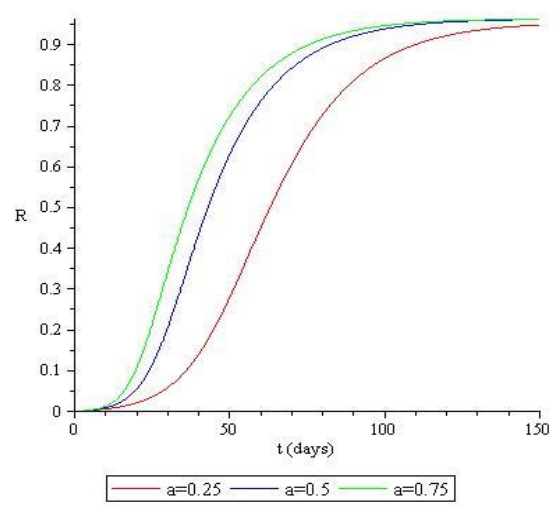

(d) Recovered

Figure 4. Dynamical simulation of SEIR with $\alpha=0$ and variation of effective contact rate 
From the dynamical simulations, it can be seen that when the virus is allowed to spread and there is no vaccination, the peak of the number of individuals exposed and infected is higher. the greater an effective contact rate, the more individuals are infected. But in terms of time, this scheme will make the span time of disease transmission decrease faster.

The following table is the estimation value of Basic Reproduction Number $R_{0}$ with variations value of effective contact rate and vaccine coverage rate.

Table 3. Basic Reproduction Number R0 with variation value of $\mathrm{a}$ and $\alpha$

\begin{tabular}{lrcc}
\hline Est. Value & $\alpha=0$ & $\alpha=10 \%$ & $\alpha=20 \%$ \\
\hline $\mathrm{a}=0.25$ & 2.2062 & 0.0654 & 0.0450 \\
$\mathrm{a}=0.5$ & 3.1201 & 0.0924 & 0.0636 \\
$\mathrm{a}=0.75$ & 3.8213 & 0.1132 & 0.0779 \\
\hline
\end{tabular}

\section{CONCLUSION}

The SEIR model is used to analyze the Covid-19 transmission model by applying the herd immunity concept. In order to obtain immunity, two schemes are discussed: (1) by using the vaccine in a group of individuals and (2) by allowing the virus to spread in a population. In the first scheme, the use of vaccines can drastically reduce the number of infected individuals. The greater the proportion of individuals who are vaccinated, the more susceptible individuals become immune to the virus and switch to the recovered compartment. As for the second scheme, when the virus is allowed to spread into population and there is no vaccination, the peak point of exposed and infected is higher compare to the first scheme. However, in terms of time, this scheme will make the span time of the covid-19 incidence go down faster.

\section{REFERENCES}

[1] C. Huang, Y. Wang, X. Li, L. Ren, J. Zhao, Y. Hu, et al, Clinical features of patients infected with 2019 novel coronavirus in Wuhan China, The Lancet, 395 (10223), 2020, pp. 497-506.

[2] World Health Organization (WHO), Coronavirus disease (COVID-19) pandemic, 2020. https://www.who.int/emergencies/diseases/novelcoronavirus-2019, Accessed on November 15, 2020.

[3] Kawal Covid 2019, Statistik Corona Seluruh Indonesia. KawalCovid19.id, Accessed on November 10, 2020.

[4] Satuan Tugas Penanganan COVID-19, Indonesia Miliki Dua Opsi Pengembangan Vaksin COVID-
19, 2019. https://covid19.go.id/p/berita/indonesiamiliki-dua-opsi-pengembangan-vaksin-covid-19

Accessed on November 12, 2020.

[5] Mayo Clinic, Herd immunity and COVID-19 (coronavirus): What you need to know, 2020. https://www.mayoclinic.org/diseasesconditions/coronavirus/in-depth/herd-immunityand-coronavirus/art-20486808 Accessed on November 12, 2020.

[6] T. Britton, F. Ball and P. Trapman, A mathematical model reveals the influence of population heterogeneity on herd immunity to SARS-CoV-2, Science, 369 (6505), 2020, pp. 846-849.

[7] T. S. Brett and P. Rohani, Transmission dynamics reveal the impracticality of COVID-19 herd immunity strategies, Proceedings of the National Academy of Sciences, 117 (41), 2020, pp. 25897 25903.

[8] P. Yu, J. Zhu, Z. Zhang, Y.A. Han, Familial Cluster of Infection Associated With the (2019) Novel Coronavirus Indicating Possible Person-toPerson Transmission During the Incubation Period, J. Infect. Dis., 221(11), 2020, pp. 1757-1761.

[9] S.A. Lauer, K.H. Grantz, Q. Bi, F.K. Jones, Q. Zheng, H.R. Meredith, et al., The Incubation Period of Coronavirus Disease 2019 (COVID-19) From Publicly Reported Confirmed Cases: Estimation and Application. Ann Int Med., 172, 2020, pp. 577-82.

[10] A.F. Huda, E.R. Wulan, F. Ilahi and M.S. Khumaeroh, Analisis pengaruh social distancing pada transmisi covid-19 dengan menggunakan model SIR, Digital Library UIN, 2020. http://digilib.uinsgd.ac.id/ Accessed on November $12,2020$.

[11] CNN Indonesia, Ahli Nilai Efektivitas Vaksin Covid-19 Minimal 50 Persen, 2020 https://www.cnnindonesia.com/teknologi/2020091 5103833-199-546575/ahli-nilai-efektivitas-vaksincovid-19-minimal-50-persen, Accessed on November 12, 2020.

[12] K. Dietz, The estimation of the basic reproduction number for infectious diseases, Statistical methods in medical research, 2(1), 1993, pp. 23-41. 